\title{
Assessment of the accuracy and role of self-recorded blood pressures in the management of hypertension
}

\author{
BRIAN A GOULD, HASSAN A KIESO, ROBERT HORNUNG, DOUGLAS G ALTMAN, \\ PETER M M CASHMAN, EDWARD B RAFTERY
}

\begin{abstract}
Self-recording of the blood pressure by patients away from hospital or office ("home blood pressure") has been advocated as providing a better estimate of "true" blood pressure. The reliability of home blood-pressure recording has been assessed only by standard indirect methods which themselves are subject to considerable error and variability. The accuracy of self-recorded blood pressures was therefore assessed in 57 patients with essential hypertension by comparison with simultaneous measurements of clinic blood pressures and with intra-arterial blood pressures recorded at home and at hospital. Home systolic blood pressures showed good agreement with clinic and intra-arterial pressures, but home diastolic blood pressures overestimated intra-arterial pressures, as did clinic diastolic pressures. The clinic and home diastolic pressures showed good agreement. There was considerable variability in individual differences comparing the indirect and intra-arterial methods, though the two indirect methods showed much closer agreement.

This study suggests that home blood pressures are as accurate as clinic readings but may be recorded more frequently and thus provide more useful information. Neither is likely to approximate the intra-arterial blood pressure.
\end{abstract}

\section{Introduction}

Many workers have found a wide range of differences comparing intra-arterial blood pressure with indirect cuff measurements. ${ }^{1-3}$ Indirect blood pressures are subject to considerable variability, ${ }^{45}$ and in order to minimise this variability serial measurements have been advised. The use of indirect methods by patients in their home surroundings permits serial blood-pressure measurements free of the tension associated with clinic visits. ${ }^{6} 7$ The accuracy of patient-recorded blood pressure, however, has not been thoroughly assessed. ${ }^{6}$ ?

We have attempted to assess the accuracy of patient-recorded measurements using the technique of intra-arterial ambulatory blood-pressure monitoring; in addition, we have compared home blood pressures, clinic blood pressures, and intra-arterial blood pressures-all recorded under standard conditions-in order to measure the relative accuracy of the indirect techniques against the standard of direct measurements.

\section{Patients and methods}

We recruited 57 patients from the hypertension clinic; 35 were receiving no medication. The group comprised 19 women and 38 men with a mean age of 52 years (range 23-70 years). The patients attended a special session of the clinic, where an indirect measurement was recorded using the Hawksley random-zero sphygmomanometer (Gelman Ltd). The patients were taught the technique of home bloodpressure measurements using a previously calibrated aneroid gauge and standard techniques ${ }^{8}$ of measurement, but using Korotkoff phase $\mathrm{V}$ for diastolic pressure. Only two patients found difficulty in mastering the technique and did not participate further; the remainder spent an average of 30 minutes in tuition. Each patient's technique of recording was checked using a double-listening stethoscope, but none of our patients was excluded from the study on the grounds of inaccurate recordings.

Home blood pressures were then recorded four times daily at set times for 10 days except on one day when the pressures were recorded hourly. During the 10 days intra-arterial ambulatory blood-pressure monitoring was performed over 48 hours using a technique which has been fully described. ${ }^{910}$ The physical characteristics and reliability of this system have been fully documented.10 During intra-arterial monitoring the patients attended the hospital at 12-hourly intervals 
for calibration and equipment checks. During these visits the blood pressure was recorded by the physician using the random-zero sphygmomanometer, after which the accuracy of the patients' technique was assessed using a double-listening stethoscope. The intra-arterial tape recording was marked with an event signal at the start of each indirect recording, both at home and in the hospital.

Indirect measurements were made on the dominant arm and the intra-arterial recordings made on the contralateral arm; for this reason a separate study to determine the pressure differences between the arms was performed. Two observers recorded the blood pressure in each arm simultaneously using one random-zero sphygmomanometer connected to both cuffs. A series of duplicate readings was made on each arm, and again after the observers had switched arms. The whole procedure was repeated after switching cuffs, so that there was a total of eight paired readings.

A hybrid computer was used to compute hourly mean pressures ${ }^{11}$ from the direct recordings, and a one-minute average blood pressure corresponding to each indirect measurement was extracted from the recordings. The reliability of this one-minute average was checked by comparing a systolic and diastolic point, taken at random, during each minute. Pressures recorded by patients at home (home blood pressures) and at hospital (patient-recorded blood pressures) and by the physician at hospital were compared with each other and with the simultaneous intra-arterial one-minute average blood pressures.

The home blood pressures for each patient were averaged over the two days of intra-arterial monitoring, and the clinic blood pressures were averaged using between five and seven measurements. The mean daytime intra-arterial pressure was calculated by computing the blood pressure in hourly sections and averaging the means of each hour between 0800 and 2000. Comparisons were then made using Student's paired $t$ test (two-tailed), though we consider the mean and variability of the differences to be more important than a significance level. A statistically significant difference of 1 or $2 \mathrm{~mm} \mathrm{Hg}$ is unimportant against the errors of indirect blood-pressure measurement. For some comparisons replicated data were obtained; they were analysed by analysis of variance to obtain the residual standard deviation (equivalent to the standard deviation obtained from unreplicated data). When considering the comparison of two methods of recording blood pressure it should be borne in mind that about $5 \%$ of patients would show differences outside the range mean $t 2 \mathrm{SD}$.

Each comparison of two methods included a scatter plot and histogram of the between-method differences. Only the lines of identity are shown in the figures; regression lines and correlation coefficients were not calculated. The correlation coefficient is a measure of association and by definition the different methods of recording the blood pressure are associated. Though frequently used for comparative analyses, the correlation coefficient gives no useful information about the agreement of the different methods of blood-pressure measurement, nor about the precision or accuracy, and may actually mislead. ${ }^{12}$

Where two methods were compared with a third (for example, clinic blood pressure and home blood pressure versus intra-arteria blood pressure) the two standard deviations of the differences wero compared by two-sided variance ratio $(F)$ tests.

\section{Results}

The blood-pressure differences between the arms showed that of the 55 patients had a mean difference of less than $5 \mathrm{~mm} \mathrm{Hg}$. No difference was greater than $9 \mathrm{~mm} \mathrm{Hg}$. The mean difference "right-left" was $2(\mathrm{SE} 0.5) /-1$ (SE 0.4) $\mathrm{mm} \mathrm{Hg}$.

Table I shows the mean and standard deviation for each measureg ment, the mean and standard deviation of between-method difference and the results of paired $t$ tests. For replicated data the pooled estimate of the mean difference and residual standard deviation were calculate⿳亠丷厂 and were almost identical with the data in table I. Table II shows comparisons of the variability of clinic and home blood pressures in relation to intra-arterial pressures by $\mathrm{F}$ tests. For each comparison $\vec{\delta}$ scatter plot and a histogram of individual differences were constructed; figures 1-4 show some of these.

TABLE II-Variance ratios (F test) comparing self-recorded blood pressure and clinic blood pressure versus intra-arterial blood pressure and self-recorded bloog pressure versus intra-arterial blood pressure recorded at home and at hospital $\mathrm{W}_{\mathrm{J}}$

\begin{tabular}{|c|c|c|c|c|}
\hline Blood pressure & No & $\begin{array}{l}\text { Residual } \\
\text { standard } \\
\text { deviation }\end{array}$ & $\mathbf{F}$ & $\mathbf{p}$ \\
\hline \multicolumn{5}{|c|}{ Systolic } \\
\hline $\begin{array}{l}\text { Home } v \text { intra-arterial } \\
\text { Clinic } v \text { intra-arterial }\end{array}$ & $\begin{array}{l}26 \\
54\end{array}$ & $\left.\begin{array}{l}16 \cdot 0 \\
11 \cdot 6\end{array}\right\}$ & 1.93 & 0.018 \\
\hline $\begin{array}{l}\text { Patient-recorded } v \text { intra-arterial } \\
\text { Home } v \text { intra-arterial }\end{array}$ & $\begin{array}{l}53 \\
26\end{array}$ & $\left.\begin{array}{r}9 \cdot 9 \\
16 \cdot 0\end{array}\right\}$ & 0.37 & 0.002 \\
\hline \multicolumn{5}{|c|}{ Diastolic } \\
\hline $\begin{array}{l}\text { Home } v \text { intra-arterial } \\
\text { Clinic } v \text { intra-arterial }\end{array}$ & $\begin{array}{l}26 \\
54\end{array}$ & $\left.\begin{array}{r}10 \cdot 8 \\
8 \cdot 7\end{array}\right\}$ & 1.54 & $0 \cdot 12$ \\
\hline $\begin{array}{l}\text { Patient-recorded } v \text { intra-arterial } \\
\text { Home } v \text { intra-arterial }\end{array}$ & $\begin{array}{l}53 \\
26\end{array}$ & $\left.\begin{array}{r}7 \cdot 3 \\
10 \cdot 8\end{array}\right\}$ & $0 \cdot 45$ & 0.015 \\
\hline
\end{tabular}

\section{Discussion}

Home blood-pressure recording is increasingly advocated as means of determining "true" blood pressure ${ }^{13}$ but there is litt/ information on the accuracy of the readings obtained by patients Most studies have excluded patients who were unable to reag the blood pressure within $5 \mathrm{~mm} \mathrm{Hg}$ of the observing physician

TABLE I-Home and clinic blood pressures compared with intra-arterial blood pressures (pressures in $\mathrm{mm} \mathrm{Hg}$ )

\begin{tabular}{|c|c|c|c|c|c|c|c|c|}
\hline Blood pressure & Mean & SD & No & $\begin{array}{c}\text { Mean } \\
\text { difference } \\
\text { between } \\
\text { values }\end{array}$ & $\begin{array}{l}\text { SD of } \\
\text { differences }\end{array}$ & $t$ & $\mathrm{n}$ & $\begin{array}{l}\text { Correspondi } \\
\text { figure }\end{array}$ \\
\hline \multicolumn{9}{|c|}{ Systolic } \\
\hline $\begin{array}{l}\text { Intra-arterial (1-minute mean) } \\
\text { Intra-arterial (one systolic point) }\end{array}$ & $\begin{array}{l}162 \\
164\end{array}$ & $\left.\begin{array}{l}28 \cdot 7 \\
28 \cdot 7\end{array}\right\}$ & 28 & -2 & $4 \cdot 4$ & $2 \cdot 9$ & $\because 0.01$ & \\
\hline $\begin{array}{l}\text { Home } \\
\text { Intra-arterial (1-minute mean) }\end{array}$ & $\begin{array}{l}164 \\
164\end{array}$ & $\left.\begin{array}{l}37 \cdot 8 \\
32 \cdot 6\end{array}\right\}$ & 27 & 0 & $23 \cdot 0$ & $0 \cdot 1$ & $>0.9$ & 1 \\
\hline $\begin{array}{l}\text { Patient-recorded (at hospital) } \\
\text { Intra-arterial (1-minute mean) }\end{array}$ & $\begin{array}{l}169 \\
173\end{array}$ & $\left.\begin{array}{l}28 \cdot 4 \\
26 \cdot 5\end{array}\right\}$ & 55 & -4 & $16 \cdot 0$ & 1.7 & $.0 \cdot 1$ & \\
\hline $\begin{array}{l}\text { Intra-arterial (mean daytime) } \\
\text { Home (2-day mean) }\end{array}$ & $\begin{array}{l}163 \\
164\end{array}$ & $\left.\begin{array}{l}23 \cdot 1 \\
26 \cdot 1\end{array}\right\}$ & 55 & -1 & $17 \cdot 0$ & 0.5 & $>0.5$ & \\
\hline $\begin{array}{l}\text { Clinic (random zero) } \\
\text { Intra-arterial (1-minute mean) }\end{array}$ & $\begin{array}{l}156 \\
169\end{array}$ & $\left.\begin{array}{l}25 \cdot 6 \\
26 \cdot 6\end{array}\right\}$ & 55 & -13 & $16 \cdot 2$ & $5 \cdot 9$ & $<0.001$ & 2 \\
\hline $\begin{array}{l}\text { Patient-recorded } \\
\text { Clinic }\end{array}$ & $\begin{array}{l}171 \\
173\end{array}$ & $\left.\begin{array}{l}34 \cdot 3 \\
35 \cdot 2\end{array}\right\}$ & 31 & -2 & $5 \cdot 9$ & $0 \cdot 4$ & $>0.5$ & 4 \\
\hline $\begin{array}{l}\text { Intra-arterial (1-minute mean) } \\
\text { Intra-arterial (one diastolic point) }\end{array}$ & $\begin{array}{l}88 \\
90\end{array}$ & $\left.\begin{array}{l}15 \cdot 5 \\
15 \cdot 1\end{array}\right\}$ & $\begin{array}{l}D i c \\
28\end{array}$ & -2 & $3 \cdot 3$ & $2 \cdot 8$ & -0.01 & \\
\hline $\begin{array}{l}\text { Home } \\
\text { Intra-arterial (1-minute mean) }\end{array}$ & $\begin{array}{l}97 \\
94\end{array}$ & $\left.\begin{array}{l}14 \cdot 4 \\
16 \cdot 5\end{array}\right\}$ & 27 & 3 & $16 \cdot 7$ & $1 \cdot 1$ & $>0 \cdot 2$ & 1 \\
\hline $\begin{array}{l}\text { Patient-recorded (at hospital) } \\
\text { Intra-arterial (1-minute mean) }\end{array}$ & $\begin{array}{r}104 \\
98\end{array}$ & $\left.\begin{array}{l}18 \cdot 9 \\
13 \cdot 7\end{array}\right\}$ & 55 & 6 & $11 \cdot 9$ & $3 \cdot 7$ & $<0.001$ & \\
\hline $\begin{array}{l}\text { Intra-arterial (mean daytime) } \\
\text { Home (1-minute mean) }\end{array}$ & $\begin{array}{r}89 \\
101\end{array}$ & $\left.\begin{array}{l}12 \cdot 9 \\
14 \cdot 0\end{array}\right\}$ & 55 & -13 & $12 \cdot 6$ & $7 \cdot 5$ & $<0.001$ & \\
\hline $\begin{array}{l}\text { Clinic (random zero) } \\
\text { Intra-arterial (1-minute mean) }\end{array}$ & $\begin{array}{l}95 \\
94\end{array}$ & $\left.\begin{array}{l}17 \cdot 7 \\
13 \cdot 0\end{array}\right\}$ & 55 & 1 & $13 \cdot 0$ & $0 \cdot 7$ & $>0.5$ & 2 \\
\hline $\begin{array}{l}\text { Patient-recorded } \\
\text { Clinic }\end{array}$ & $\begin{array}{l}103 \\
101\end{array}$ & $\left.\begin{array}{l}21 \cdot 6 \\
19 \cdot 4\end{array}\right\}$ & 31 & 2 & $7 \cdot 0$ & $1 \cdot 6$ & $>0.1$ & 4 \\
\hline
\end{tabular}



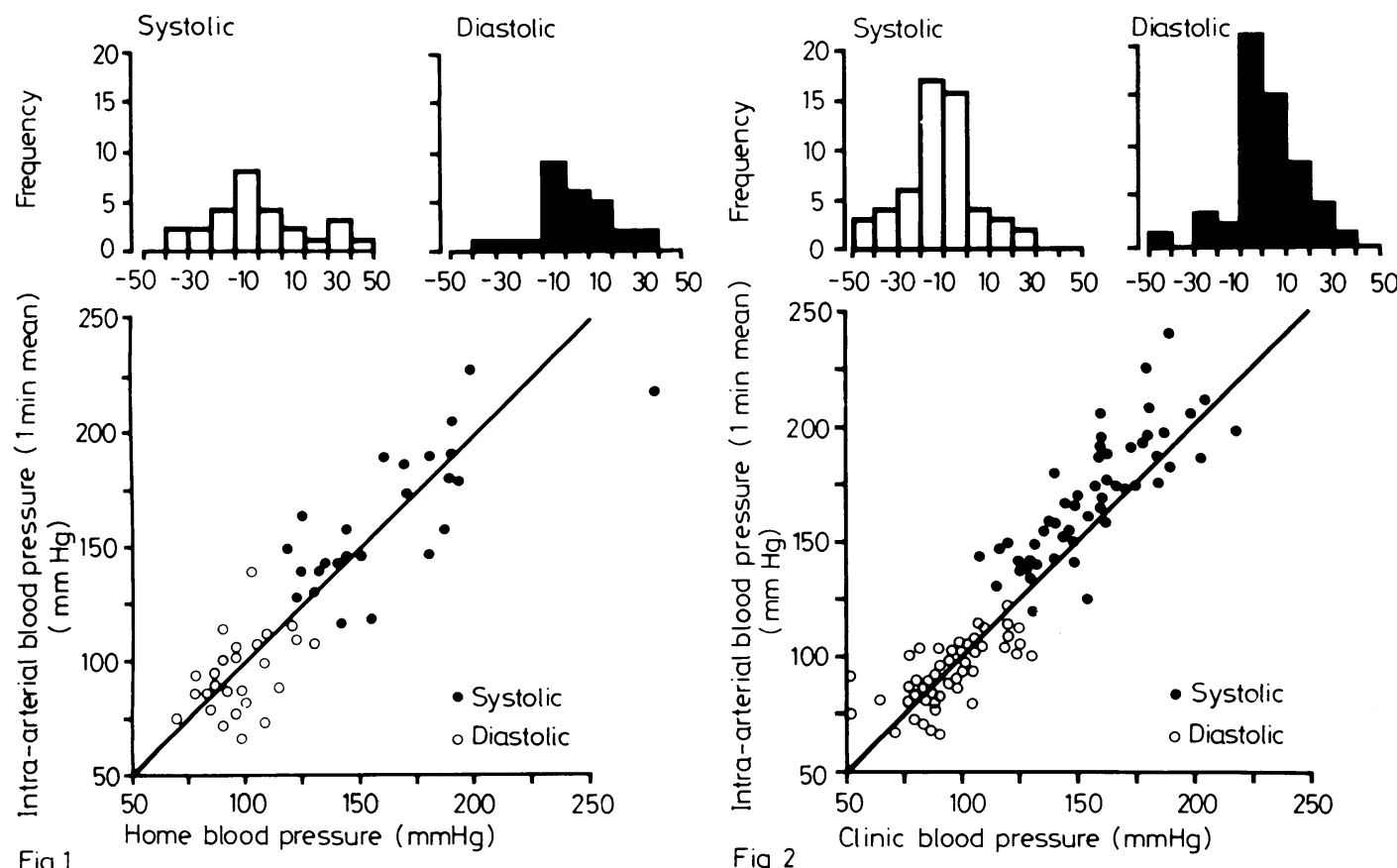

Fig 1

\section{Fig 2}
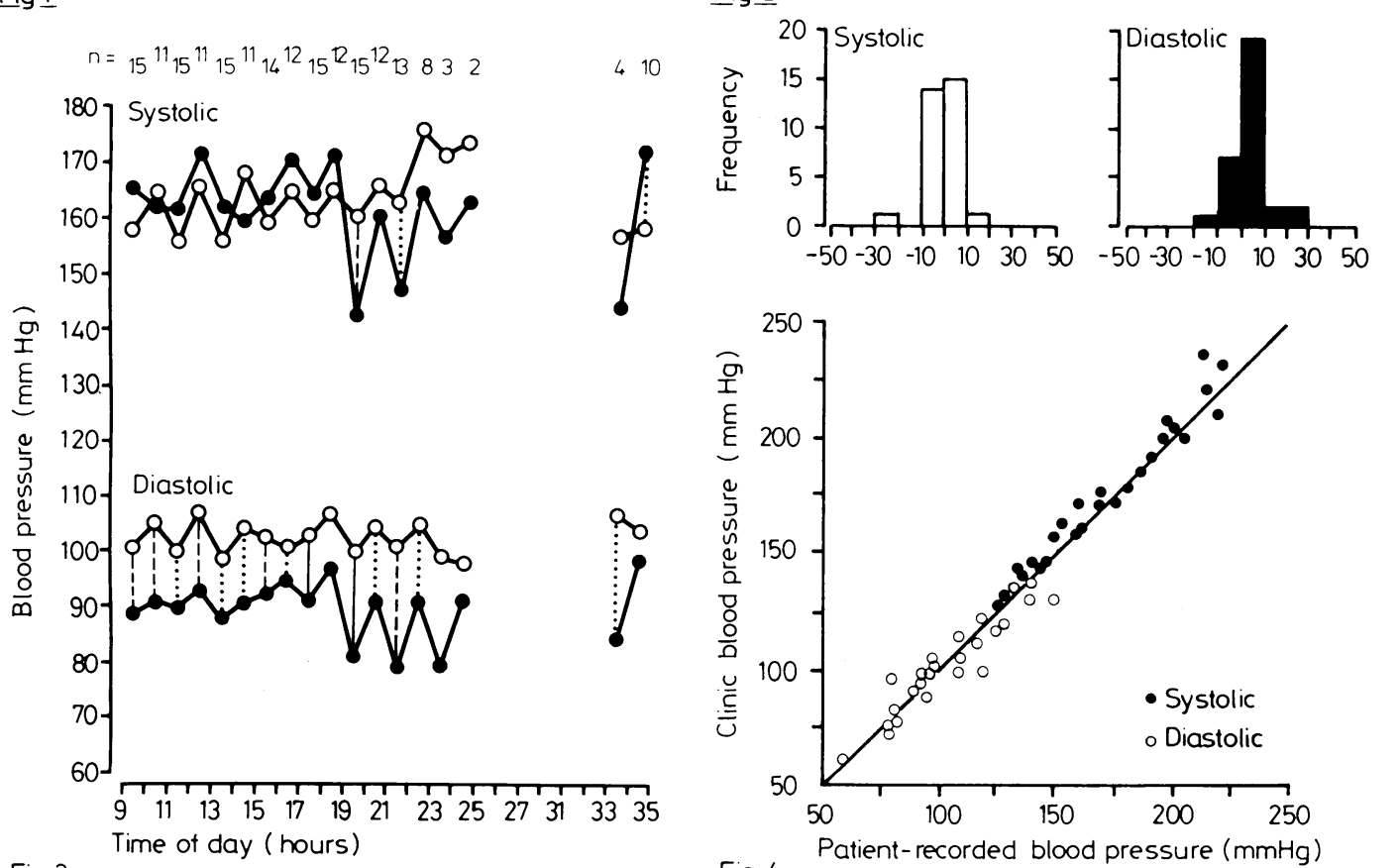

FIG 1-Scatter plot and frequency histogram of home blood pressure-intra-arterial blood pressure (1 minute mean). Line shown in scatter plot is line of identity. Frequency histogram: systolic blood pressure $-47 \%$ within \pm 10 $\mathrm{mm} \mathrm{Hg}$, diastolic blood pressure $-55 \%$ within $+10 \mathrm{~mm} \mathrm{Hg}$ (that is, $47 \%$ of systolic home blood pressures were within $10 \mathrm{~mm} \mathrm{Hg}$ of intra-arterial pressure).

FIG 2-Scatter plot of clinic blood pressure-intra-arterial blood pressure (1 minute mean).

Frequency histogram: systolic blood pressure $-36 \%$ within $t 10$ $\mathrm{mm} \mathrm{Hg}, 67 \%$ within -20 to +10 $\mathrm{mm} \mathrm{Hg}$; diastolic blood pressure $-65 \%$ within $\pm 10 \mathrm{~mm} \mathrm{Hg}$.

FIG 3-Trend plot of hourly mean intra-arterial blood pressure (O) compared with hourly home-recorded blood pressure ( $)(. . . \mathrm{p}<0.05 ;---\mathrm{p}<0.01$; $\mathrm{p}<0.001)$.

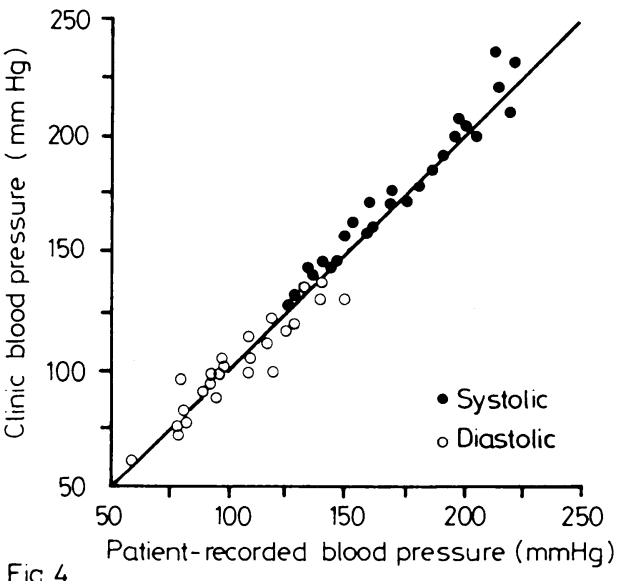

FIG 4-Scatter plot and frequency histogram of patient-recorded blood pressure-clinic blood pressure (laboratory data). Frequency histogram: systolic blood pressure $-93 \%$ within $\pm 10 \mathrm{~mm}$ $\mathrm{Hg}$; diastolic blood pressure $-83 \%$ within $+10 \mathrm{~mm} \mathrm{Hg}$.

during simultaneous auscultation. This is open to the criticism that there may be an interaction between the patient and observer over recognising the Korotkoff sounds which might lead to biased results. In addition, trained observers may vary considerably when recording the blood pressure, ${ }^{14}{ }^{16}$ and the same observer may vary when reading the same pressure from a test film. For these reasons we considered it necessary to make comparison with direct measurements, which are not subject to the same variability as indirect methods. The use of intraarterial ambulatory monitoring also allowed a check on the accuracy of home-recorded pressures which were measured away from the presence of a physician. In this study no patients were excluded and only two patients were unable to learn and apply the technique.

The validity of using a one-minute mean pressure from the intra-arterial record as a standard was checked by comparing this mean with a single random systolic and diastolic beat recorded during the same minute. The results (table I) showed that there was no significant difference.

The most important finding in this study was the wide scatter of data when comparing simultaneous indirect and intra-arterial blood pressures (figs 1 and 2), differences of up to $50 \mathrm{~mm} \mathrm{Hg}$ being recorded. While occasional large individual differences were obtained, the trend plots (fig 3 ) of hourly means compared favourably, suggesting that for a group of patients a reasonable estimate of blood-pressure patterns can be obtained by homerecorded pressures. There was only a slight difference between the variability of patient-recorded and clinic blood pressures in relation to intra-arterial pressures. Blood pressures recorded in hospital showed better agreement with intra-arterial blood pressures than did those recorded at home (tables I and II). The clinic pressure recorded with the random-zero sphygmomanometer was systematically lower than simultaneous intra-arterial pressures (mean $13 / 1 \mathrm{~mm} \mathrm{Hg}$ ) (table I). It may be concluded that the indirect methods gave only a rough estimate of the intra-arterial blood pressure and that there was little to choose between clinic-recorded or home-recorded pressures for accuracy. Home-recorded pressures, however, provided more readings throughout the day, and this information might have a clinical value of its own. 
As mentioned above, simultaneous recordings of the blood pressure by a physician and patient may lead to biased results, and our data confirmed that this may happen (fig 4, table I). The mean difference of this patient-clinic comparison was -2 (SD 5.0)/2 (SD 7.0) $\mathrm{mm} \mathrm{Hg}$.

Similar discrepancies were reported by Joossens et al, ${ }^{16}$ who found a mean "patient-clinic" difference of $0 \cdot 19$ (SD 3.7)/4 (SD 3.5) $\mathrm{mm} \mathrm{Hg}$. Julius et $\mathrm{al}^{7}$ reported a mean "patient-clinic" difference of $-3 / 7 \mathrm{~mm} \mathrm{Hg}$, while Laughlin et al reported a difference of $-11 /-5 \mathrm{~mm} \mathrm{Hg}$. The differences between the above comparisons probably result from the variability of the indirect methods.

Home blood pressures and indirect clinic measurements appeared to show good agreement, but neither indirect method accurately reflected the intra-arterial blood pressure. Home blood-pressure measurements are therefore subject to the same constraints as clinic measurements. Intra-arterial ambulatory monitoring remains the most accurate and well-defined method, but has a specific application as a research technique and cannot replace the indirect method of blood-pressure measurement. Home blood-pressure recording as an alternative may have a role in characterising populations and defining the efficacy of antihypertensive agents, but its limitations as a technique must be taken into account before conclusions can be drawn from the results.

We thank Mr S Dashwood for technical help and the CRC word processing department for typing the manuscript.

\section{References}

1 Ragan C, Bordley J. The accuracy of clinical measurements of arterial blood pressure. Bulletin of the fohns Hopkins Hospital 1941 ;69:504-28. 2 Roberts LN, Smiley JR, Manning GW. A comparison of direct and indirect blood pressure determinations. Circulation $1953 ; 8: 232-42$.
${ }^{3}$ Raftery EB, Ward AP. The indirect method of recording blood pressure Cardiovasc Res 1968;2:210-8.

${ }^{4}$ Armitage P, Rose GA. The variability of measurements of causal bloo pressure. I. A laboratory study. Clin Sci 1966;30:325-35.

${ }^{5}$ Armitage P, Fox W, Rose GA, Tinker CM. The variability of measurements of causal blood pressure. II. Survey experience. Clin Sci 1966 $\mathbf{3 0}: 337-44$.

6 Ayman D, Goldshine AD. Blood pressure determinations by patients wit essential hypertension. 1. The difference between clinic and homg readings before treatment. Am $\mathcal{F}$ Med $S c i$ 1940;200:465-94.

${ }^{7}$ Julius S, McGinn NF, Harburg E, Hoobler SW. Comparison of varioup clinical measurements of blood pressure with the self determination technique in normotensive college males. F Chronic Dis 1964;17:391-6:

* Kirkendall WM, Burton AC, Epstein FH, Freis ED. Report to th American Heart Association: recommendations for human bloơ pressure determination by sphygmomanometers. Circulation 1967;3 980-8.

${ }^{9}$ Bevan AT, Honour AJ, Stott FD. Direct arterial pressure recording $\frac{\overline{\bar{m}}}{\overline{\frac{\mathrm{m}}{9}}}$ unrestricted man. Clin Sci $1969 ; \mathbf{3 6}: 329-44$.

${ }^{10}$ Millar-Craig MW, Hawes D, Whittington J. New system for recordin尺 ambulatory blood pressure in man. Med Biol Eng Comput 1978;1@ 727-31.

11 Cashman PMM, Stott FD, Millar-Craig MW. Hybrid system for fast da $\vec{\Phi}$ reduction on long term blood pressure recordings. Med Biol Eng Comput 1979;17:629-35.

12 Altman DG. Bland JM. Measurement in medicine: the analysis of metho comparison studies. Statistician (in press).

${ }^{13}$ Laughlin KD, Sherrard DJ, Fisher L. Comparison of clinic and hore. blood pressure levels in essential hypertension and variables associated with clinic-home differences. $\mathcal{F}$ Chronic Dis 1980;33:197-206.

14 Wilcox J. Observer factors in the measurement of blood pressure. $f A M$ के $1962 ; 179: 53$.

${ }^{15} \mathrm{King}$ GE. MD thesis. Some sources of error in the clinical measureme of blood pressure. University of London, 1967.

16 Joossens JV, Brems-Heyns E, Claessens J. The value of home blooe pressure recordings. A tool for epidemiological studies. In: Kesteloof $\mathrm{W}$, ed. Commission of the European Communities Biological Sciences $\frac{\mathrm{O}}{3}$ Medical Research. Methodology and standardisation of non-invasive blood. pressure measurement in epidemiological studies. Proceedings of a workshop in Leuven (Belgium), 1974. Brussels, Belgium: Commission of the European Communities, Directorate General "Research and Education 1976.

(Accepted 8 October 1982)

\section{, ,}

The GREAT ROUND-LEAVED DOLK, OR BASTARD RHUBARB has divers large, round thin yellowish green leaves rising from the root, a little waved about the edges, every one standing upon a reasonably thick and long brownish footstalk, from among which rises up a pretty big stalk, about two feet high, with some such high leaves growing thereon, but smaller; at the top whereof stand in a long spike many small brownish flowers, which turn into a hard three square shining brown seed, like the garden Patience before described. The root grows greater than that, with many branches or great fibres thereat, yellow on the outside, and somewhat pale; yellow within, with some discoloured veins like to the Rhubarb which is first described, but much less than it, especially when it is dry.

These also grow in gardens, and flower and seed at or near the same time that our true Rhubarb doth, viz they flower in June, and the seed is ripe in July.

Mars claims predominancy over all these wholesome herbs: You cry out upon him for an unfortunate, when God created him for your good (only he is angry with fools). What dishonour is this, not to Mars, but to God himself. A dram of the dried root of Monk's Rhubarb, with a scruple of Ginger made into powder, and taken fasting in a draught or mess of warm broth, purges choler and phlegm downwards very gently and safely without danger. The seed thereof contrary doth bind the belly, and helps to stay any sort of lasks or bloody-flux. The distilled water thereof is very profitably used to heal scabs; also foul ulcerous sores, and to allay the inflammation of them; the juice of the leaves or roots or the decoction of them in vinegar, is used as the most effectual remedy to heal scabs and running sores.

The Bastard Rhubarb hath all the properties of the Monk's Rhubarb, but more effectual for both inward and outward diseases. The decoction thereof without vinegar dropped into the ears, takes away the pains; gargled in the mouth, takes away the tooth ache; and being drank, heals the jaundice. The seed thereof taken, eases the gnawing and griping pains of the stomach, and takes away the loathing thereof unto meat. The root thereof helps the ruggedness of the nails, and being boiled in wine helps the swelling of the throat, commonly called the king's evil, as also the swellings of the kernels of the ears It helps them that are troubled with the stone, provokes urine, an $\$$ helps the dimness of the sight. The roots of this Bastard Rhubarb ar used in opening and purging diet-drinks, with other things, to ope the liver, and to cleanse and cool the blood.

The properties of that which is called the English Rhubarb are the same with the former, but much more effectual, and hath all the properties of the true Italian Rhubarbs, except the force in purging, wherein it is but of half the strength thereof, and therefore a double quantity must be used: it likewise hath not that bitterness an astriction; in other things it works almost in an equal quantity, whic are these: It purges the body of choler and phlegm, being either taker of itself, made into powder, and drank in a draught of white wine, or steeped therein all night, and taken fasting, or put among otheo purges, as shall be thought convenient, cleansing the stomach, liver? and blood, opening obstructions, and helping those griefs that como thereof, as the jaundice, dropsy, swelling of the spleen, tertain and daily agues, and pricking pains of the sides; and also stays spittings of blood. The powder taken with cassia dissolved, and washed Venices turpentine, cleanses the reins and strengthens them afterwards, and. is very effectual to stay the gonorrhea. It is also given for the pain and swellings in the head, for those that are troubled with melancholy and helps the sciatica, gout, and the cramp. The powder of the Rhu $\omega$ barb taken with a little mummia and mander roots in some red wine $\bar{C}$ dissolves clotted blood in the body, happening by any fall or bruises and helps burstings and broken parts, as well inward as outward. The oil likewise wherein it hath been boiled, works the like effects being? anointed. It is used to heal those ulcers that happen in the eyes oro eyelids, being steeped and strained; as also to assuage the swellingso and inflammations; and applied with honey, boiled in wine, it takesब away all blue spots or marks that happen therein. Whey or white wine are the best liquors to steep it in, and thereby it works more effectual in opening obstructions, and purging the stomach and liver. Many do use a little Indian Spikenard as the best corrector thereof. (Nicholas Culpeper (1616-54) The Complete Herbal, 1850.)

\section{.}

